\title{
Rapid detection method of ship ballast water biomass based on spectrophotometry
}

\author{
Yue Lin, Haibo Li, Gonghui Zhang, Zhenhui Chen, Yang Liu
}

\begin{abstract}
The invasive aquatic species carried by ship ballast water has caused serious environmental damage and great economic loss worldwide. The issue of ship ballast water discharge has received extensive attention in recent years. According to the IMO Ballast Water Management Convention, The vast majority vessels must perform ballast water treatment that complies with a set of parameters according to regulation D-2. Thus, it is urgent to solve the problem of testing the quantity of organisms in ballast water. But few report has been made on the fast microbial counting method that can really support the D-2 standard in ship ballast water and the existing technology methods have obvious disadvantages. In the study, we reported a rapid detection method of ship ballast water biomass based on spectrophotometry. This method can be used for rapid and convenient detection of microalgae cell biomass of 10-50um in ship ballast water, and has the advantages of portability, speed, simplicity and no need of fluorescence probe.
\end{abstract}

Index Terms - spectrophotometry; ballast water; long optical;microorganisms.

\section{INTRODUCTION}

Due to the rapid development of shipping industry in recent years, the invasive aquatic species carried by ship ballast water has caused serious environmental damage and great economic loss worldwide[1-3]. International Maritime Organization (IMO) Ballast water Management convention had been come into force on 8 September 2017. According to the IMO Ballast Water Management Convention, regulation D-2 of the Convention stipulates that ships meeting the requirements of the Convention must discharge:

- less than 10 viable organisms per cubic meter greater than or equal to 50 micrometers in minimum dimension.

- less than 10 viable organisms per millilitre less than 50 micrometers in minimum dimension and greater than or equal to 10 micrometers in minimum dimension.

The convention puts forward new requirements on the performance ability of maritime administrative bodies. The competent maritime authority is about to carry out PSC inspection on ships in port under this convention[4]. For shipowners, the D-2 standard also imposes new requirements on them. Before the international maritime organization marine environmental protection committee, new ships built

Yue Lin Merchant Marine academy, Shanghai Maritime University, shanghai 200135, PR China.

Haibo Li College of Marine Science and Engineering, Shanghai Maritime University, shanghai 200135, PR China.

Gonghui Zhang College of Marine Science and Engineering, Shanghai Maritime University, shanghai 200135, PR China.

Zhenhui Chen College of Marine Science and Engineering, Shanghai Maritime University, shanghai 200135, PR China.

Yang Liu Merchant Marine academy, Shanghai Maritime University, shanghai 200135, PR China. on or after September 8, 2017 shall comply with D-2 standards from the date of delivery [5]-[6]. Thus, it is urgent to solve the problem of testing the quantity of organisms in ballast water.

But few report has been made on the fast microbial counting method that can really support the D-2 standard in ship ballast water. The method, fluorescent probe staining and microscopic examination, has been widely used presently. However, this method has the disadvantages of high lower limit, time consuming and high detection intensity. The detection result is questionable because a single fluorescent probe is not effective against all living organisms[7]. Thus, many researchers and companies have worked on increasing the number of fluorescent probes and used more efficient and reliable detection instruments, such as Flow Cytometry (FCM)[8]-[10] and Microfluidic Chip[11]-[12].But the current research can only be done in the laboratory, not in practice. In addition, the government regulatory authorities also lack of effective means of on-site monitoring of the discharge of ballast water from ships[13]-[15].

In the present paper, we reported a rapid detection method of ship ballast water biomass based on spectrophotometry. In this method, it is assumed that photosynthetic microalgae are the main living microorganisms in ship ballast water. The number of living microorganisms in ballast water can be estimated roughly by detecting chlorophyll content in ballast water. The device described below can be used for rapid and convenient detection of microalgae cell biomass of $10-50 \mu \mathrm{m}$ in ship ballast water. This method realizes the rapid detection of microalgae cells, and has the advantages of portability, speed, simplicity and no need of fluorescence probe.

\section{METHOD AND PROCESS}

The long path flow cell (LPC-500CM, optical path $500 \mathrm{~cm}$, Wavelength Range 280-730 $\mathrm{nm}$ ) were purchased from Oceanoptics Co.Ltd. Acetone were purchased from Sinopharm Chemical Reagent Co. Ltd. Deionized water is used in the gas water backwashing device. The detection system is shown in figure 1 .

The ballast water sample to be tested is introduced into the sampling chamber, and the sampling valve, the liquid discharging valve and the sampling pump are turned on. The sample is driven by the pump into the concentrator device (the volume of the concentrator device is $0.5 \mathrm{ml}$, and the filter at the lower end is provided with a pore size of $50 \mu \mathrm{m}$, The upper end outlet is provided with a filter with a pore size of $10 \mu \mathrm{m}$ ) which intercepts $10-50 \mu \mathrm{m}$ size of organisms, and the remaining liquid is discharged into the waste tank. The final concentration sample is displayed and controlled by a sampling flow meter to be $500 \mathrm{ml}$. Then, the flush valve is opened, and the gas-water backwash device backwashes the 
filter at the upper outlet of the concentrator device so that organisms remaining on the filter can enter the concentrated sample. Open the inlet valve and the lysis valve, and the concentrated sample through the lysis chamber (Normally no need to add lysate) into the long path flow cell. After the flow meter shows that the concentrated sample has passed $150 \mathrm{ul}$, the spectrometer starts to measure the absorbance of the concentrated sample in the long path flow cell (read the absorbance at $750 \mathrm{~nm}, 663 \mathrm{~nm}, 645 \mathrm{~nm}$, and $630 \mathrm{~nm}$, respectively), and repeat the absorbance measurement at a higher frequency. The sample continues to flow through the long path flow cell during the measurement and eventually flows into the recycling device.

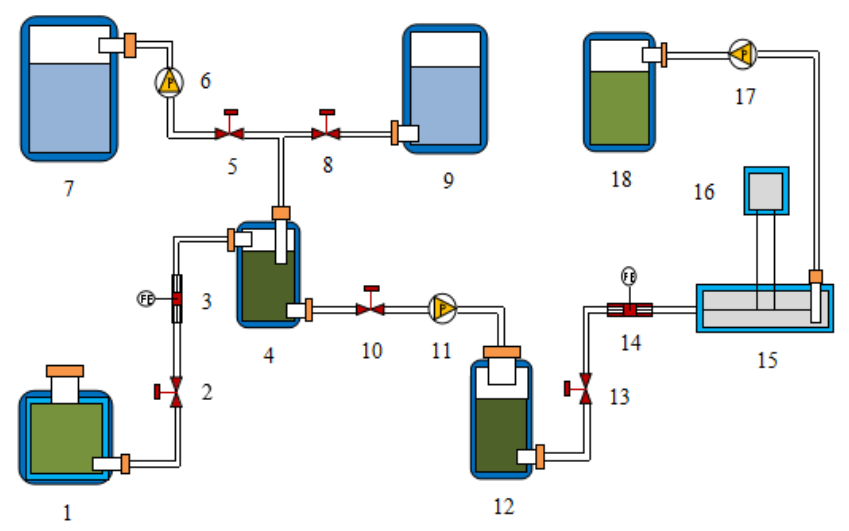

Figure 1. Schematic diagram of ship ballast water rapid detection

\author{
1. Sampling chamber \\ 2. Sampling valve \\ 3. Sampling flow meter \\ 4. Concentrator device \\ 5. Drain valve \\ 6. Sampling pump \\ 7. Waste tank \\ 8. Flush valve \\ 9. Gas water backwashing device \\ 10. Inlet valve \\ 11. Inlet pump \\ 12. Lysis chamber \\ 13. Lysis valve \\ 14. Inlet flow meter \\ 15. Long path flow cell \\ 16. Spectrometer \\ 17. Drain pump \\ 18. Recycling device
}

The computer connected to the spectrometer performs statistical analysis on the repeatedly measured data, which rejects the individual abnormal data automatically (refers to the measured value of the set of values that deviates from the average value by more than twice the standard deviation) and performs the mean calculation on the remaining data. The content of chlorophyll is calculated by the following calculation formula, and the corresponding biomass concentration in the initial ballast water is converted. (measuring chlorophyll $\alpha$ and calculating biomass concentration in this study is actually a semi-quantitative method, which relying on a large number of water sample data to establish a perfect database as the basis in the actual operation). When the microbial concentration is less than 10 per $\mathrm{ml}$, the judgment result is qualified; when the biomass concentration is not less than 10 per $\mathrm{ml}$, the judgment result shows no qualified.

For ballast water samples with higher turbidity, the process of sampling, concentration, and backwashing in the test is consistent with the above. The difference is after the concentrated sample enters the lysis chamber, the lysis buffer added (the lysis buffer is acetone). After standing for 5 minutes, the lysis valve is opened and the concentrated sample enters the long-path flow cell after the lysis process. The subsequent steps and methods are the same as described above.

\section{PRINCIPLE AND MECHANISM}

Calculation formula[16]-[17]:

Chlorophyll $\alpha=$

(11.64×(D663-D750)-2.16×(D645-D750)+0.10×(D630-D750) $) \times V 1$

$$
(\mathrm{V} \times \delta)
$$

$\mathrm{V}$ - the volume of the water sample (the volume of the water sample through the sampling flowmeter during the detection process) (L)

D__absorbance

V1— the volume after the constant volume of the extract (the actual volume of the concentrator) (ml)

$\delta$ - optical path of cuvette $(\mathrm{cm})$

The purpose of measuring the absorbance at a wavelength of $750 \mathrm{~nm}$ is to avoid interference of suspended matter. Generally, the wavelength used for measuring turbidity in water is $680 \mathrm{~nm}$. To avoid the absorption value of chlorophyll $\alpha$ at $680 \mathrm{~nm}$, the wavelength of turbidity will be selected above $710 \mathrm{~nm}$.

In the calculation formula, the absorbance values at 750 $\mathrm{nm}$ should be subtracted from the absorbance values at 750 $\mathrm{nm}$ to deduct the interference of suspended matter, and the values should be less than $5 \%$ of the absorbance value of the chlorophyll $\alpha$ absorption peak (D750 < 5\% D663; D750 < 5\% D645; D750 $<5 \%$ D630. Assuming that the absorbance value of the sample at $663 \mathrm{~nm}$ is 0.03 , the absorbance at $750 \mathrm{~nm}$ should not be greater than 0.0015 , which requires high clarity of the test solution. Otherwise, it should be re-filtered and the concentration factor reduced (the concentration factor is reduced to $1 / 2$ ).

If the detection result after reducing the concentration factor (the concentration factor is reduced to $1 / 2$ ) is still that the absorbance value at $750 \mathrm{um}$ is not less than $5 \%$ of the absorbance value of chlorophyll $\alpha$ absorption peak, the enhancement measure of adding cell lysate is adopted.

\section{SUMMARY}

Based on the long-path flow cell and the method of spectrophotometric determination of chlorophyll $\alpha$, we designed a method for detecting 10-50um microalgae cells in ship ballast water, and realized the rapid detection of microalgae cells in ship ballast water. Compared with the detection methods currently reported, this method has the advantages of simple device structure, convenient operation, efficient detection process, independent of fluorescent dyes, and no shaking of the ship. It can quickly determine the microalgae cell biomass in the sample and thus provide a means for maritime law enforcement to effectively and quickly detect ballast water. The new method proposed in this paper has the following technical characteristics:

1) Calculating the concentration of chlorophyll $\alpha$ in ballast 
water by spectrophotometry and calculation formula , and then converting the concentration of the microalgae cells biomass.

2) By increasing the optical path, the concentration factor required for the sample is reduced, thereby greatly reducing the sampling amount and saving the time required for concentration. (using a long optical path flow cell is to increase the optical path. The standard cell optical path is $1 \mathrm{~cm}$, and this method chooses to use a $500 \mathrm{~cm}$ long path flow cell).

3) Multiple sets of absorbance data can be obtained by repeated measurement at higher frequencies. By statistical analysis of these data, the detection accuracy can be effectively improved and the invalid samples can be identified, and the reliability of the test results can be improved.

\section{REFERENCES}

[1] A. Rey, O.C. Basurko, N. Rodríguez-Ezpeleta, The challenges and promises of genetic approaches for ballast water management, Journal of Sea Research, 133 (2018) 134-145.

[2] R. Balaji, O. Yaakob, K.K. Koh, A review of developments in ballast water management, Environmental Reviews, 22 (2014) 298-310.

[3] E. Tsolaki, E. Diamadopoulos, Technologies for ballast water treatment: a review, Journal of Chemical Technology \& Biotechnology, 85 (2010) 19-32.

[4] W. Batista, F. Fernandes, C. Lopes, R. Lopes, W. Miller, G. Ruiz, Which Ballast Water Management System Will You Put Aboard? Remnant Anxieties: A Mini-Review, Environments, 4 (2017) 54.

[5] E.R. Holm, D.M. Stamper, R.A. Brizzolara, L. Barnes, N. Deamer, J.M. Burkholder, Sonication of bacteria, phytoplankton and zooplankton: Application to treatment of ballast water, Marine pollution bulletin, 56 (2008) 1201-1208.

[6] I.C. Davidson, M.S. Minton, K.J. Carney, A.W. Miller, G.M. Ruiz, Pioneering patterns of ballast treatment in the emerging era of marine vector management, Marine Policy, 78 (2017) 158-162.

[7] K. Lundgreen, H. Holbech, K.L. Pedersen, G.I. Petersen, R.R. Andreasen, C. George, G. Drillet, M. Andersen, UV fluences required for compliance with ballast water discharge standards using two approved methods for algal viability assessment, Marine pollution bulletin, 135 (2018) 1090-1100.

[8] R.O. Olsen, F. Hoffmann, O.K. Hess-Erga, A. Larsen, G. Thuestad, I.A. Hoell, Ultraviolet radiation as a ballast water treatment strategy: Inactivation of phytoplankton measured with flow cytometry, Marine pollution bulletin, 103 (2016) 270-275.

[9] D.A. Wright, N.A. Welschmeyer, L. Peperzak, Alternative, indirect measures of ballast water treatment efficacy during a shipboard trial: a case study, Journal of Marine Engineering \& Technology, 14 (2015) $1-8$.

[10] M.C. Trindade de Castro, M.J.W. Veldhuis, Temporal changes in phytoplankton biomass and cellular properties; implications for the IMO ballast water convention, Environmental technology, 40 (2019) 1455-1466.

[11] Y. Song, J. Wang, J. Yang, Y. Wu, N. Li, N. Gong, X. Pan, Y. Sun, D. $\mathrm{Li}$, Algae Detection and Ship's Ballast Water Analysis by a Microfluidic Lab-on-Chip Device, Instrumentation Science \& Technology, 40 (2012) 305-315.

[12] M. Maw, J. Wang, F. Li, J. Jiang, Y. Song, X. Pan, Novel Electrokinetic Microfluidic Detector for Evaluating Effectiveness of Microalgae Disinfection in Ship Ballast Water, International Journal of Molecular Sciences, 16 (2015) 25560-25575.

[13] M. David, J. Linders, S. Gollasch, J. David, Is the aquatic environment sufficiently protected from chemicals discharged with treated ballast water from vessels worldwide? - A decadal environmental perspective and risk assessment, Chemosphere, 207 (2018) 590-600.

[14] O.K. Hess-Erga, J. Moreno-Andres, O. Enger, O. Vadstein, Microorganisms in ballast water: Disinfection, community dynamics, and implications for management, The Science of the total environment, 657 (2019) 704-716.

[15] D.A. Wright, R. Dawson, V. Caceres, C.E. Orano-Dawson, G.E. Kananen, S.J. Cutler, H.G. Cutler, Shipboard testing of the efficacy of SeaKleen as a ballast water treatment to eliminate non-indigenous species aboard a working tanker in Pacific waters, Environmental technology, 30 (2009) 893-910.

[16] G. Casasanta, R. Garra, Towards a Generalized Beer-Lambert Law, Fractal and Fractional, 2 (2018) 8.

[17] W. Blanken, P.R. Postma, L. de Winter, R.H. Wijffels, M. Janssen, Predicting microalgae growth, Algal Research, 14 (2016) 28-38. 